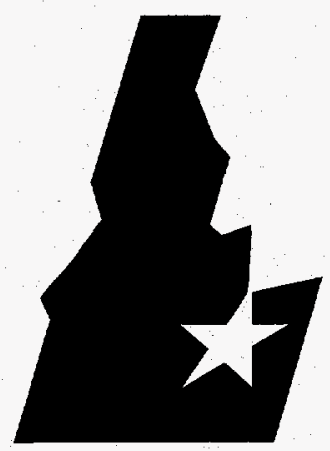

Idaho

National

Engineering Laboratory
RECEIVED June 1998 JUL 101998

\section{$08 T 1$}

Parameter Selection For Department of Energy Spent Nuclear Fuel To Be Used in The Yucca Mountain Viability Assessment

\section{D.L. Fillmore}
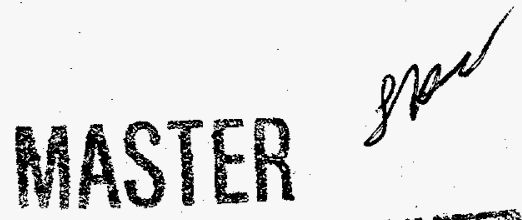

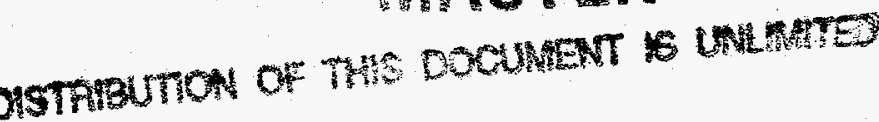




\section{DISCLAIMER}

This report was prepared as an account of work sponsored by an agency of the United States Government. Neither the United States Government nor any agency thereof, nor any of their employees, makes any warranty, express or implied, or assumes any legal liability or responsibility for the accuracy, completeness, or usefulness of any information, apparatus, product, or process disclosed, or represents that its use would not infringe privately owned rights. Reference herein to any specific commercial product, process, or service by trade name, trademark, manufacturer, or otherwise does not necessarily constitute or imply its endorsement, recommendation, or favoring by the United States Government or any agency thereof. The views and opinions of authors expressed herein do not necessarily state or reflect those of the United States Government or any agency thereof. 


\section{DISCLAIMER}

Portions of this document may be illegible electronic image products. Images are produced from the best available original document. 


\title{
Parameter Selection For Department of Energy Spent Nuclear Fuel To Be Used in The Yucca Mountain Viability Assessment
}

\author{
D. L. Fillmore
}

Published June 1998

Idaho National Engineering and Environmental Laboratory

Lockheed Martin Idaho Technologies Company

Idaho Falls, Idaho 83415

Work supported by the

U.S. Department of Energy,

Office of Environmental Management (EM), under DOE Idaho Operations Office

Contract DE-AC07-94D1 3223. 



\section{ABSTRACT}

This report contains the chemical, physical, and radiological parameters that were chosen to represent the Department of Energy Spent Nuclear Fuel in the Yucca Mountain Viability Assessment. It also contains the selected packaging requirements for the various fuel types and the criticality controls that were used. The data is reported for representative fuels in groups of fuels that were selected for the analysis. The justification for the selection of each parameter is given. The data reported was not generated under any $Q$. A. Program. 



\section{CONTENTS}

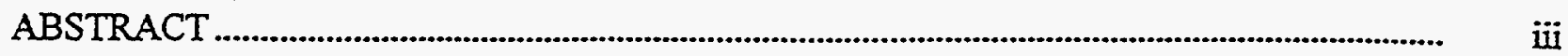

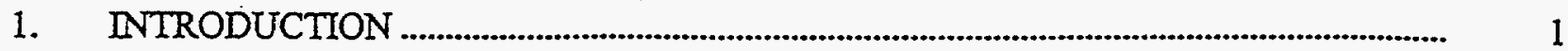

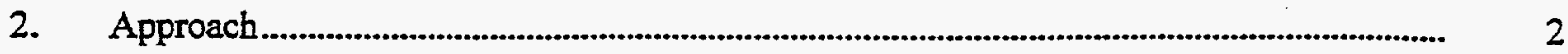

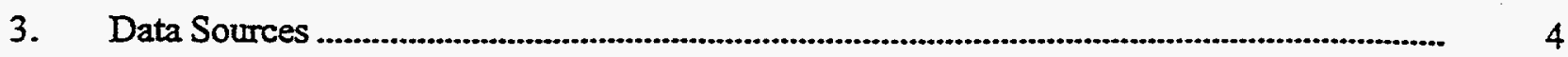

4. DOE SNF Data Presented by Total System Performance Assessment Groups ....................... 5

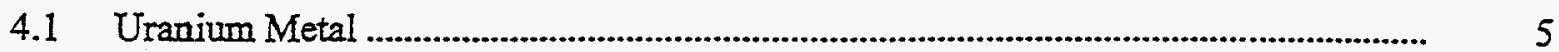

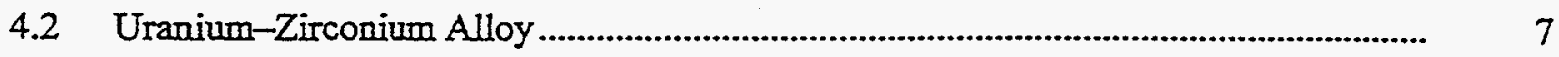

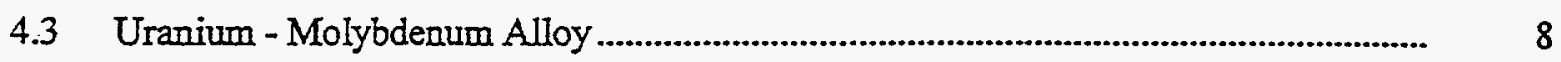

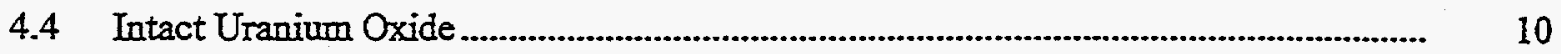

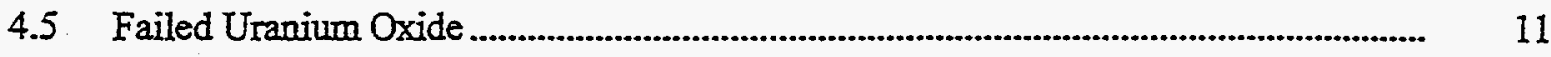

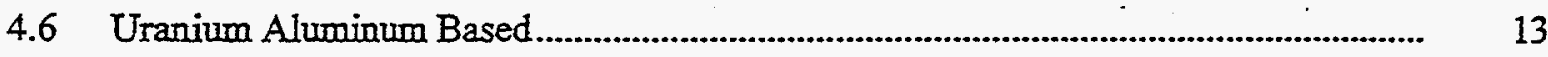

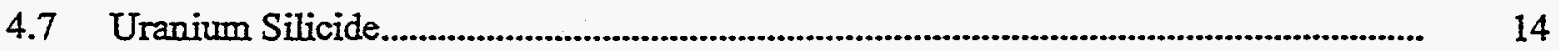

4.8 High Integrity Uranium-Thorium Carbide .............................................................. 16

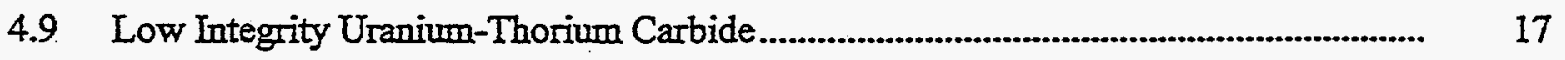

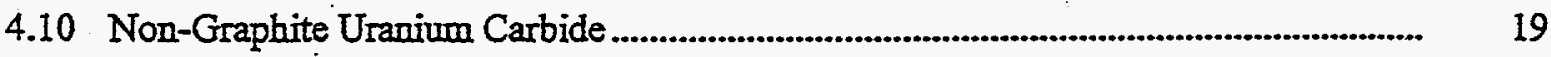

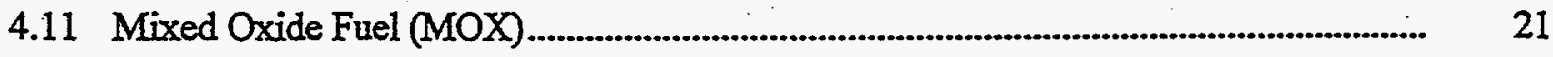

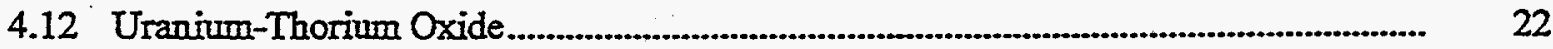

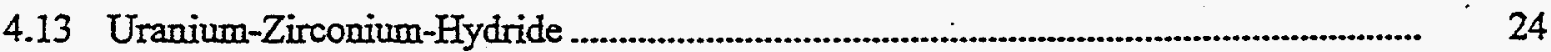

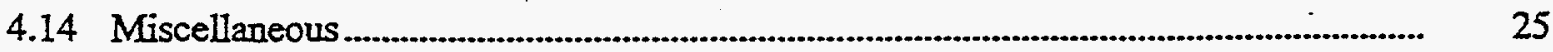





\section{Parameter Selection \\ For Department of Energy Spent Nuclear Fuel \\ To Be Used in The \\ Yucca Mountain Viability Assessment}

\section{INTRODUCTION}

To perform a Total System Performance Assessment (TSPA) on the DOE SNF, it is necessary to obtain data on the characteristics and performance of the DOE fuel in a repository setting. RW has a good data base of characteristics of commercial SNF due to many years of research and characterization studies. No such data base exists for the DOE SNF. There has been some research in a few performance parameters that could be applied to the DOE SNF inventory and some of the Commercial SNF parameters can be adapted or modified as deemed appropriate to obtain the parameters for analysis of the DOE SNF. In some cases, best engineering judgement has to be used to estimate the parameter, because there is no existing data on the SNF. In these cases, groups of knowledgeable individuals met to make the estimates.

The data requested for the DOE SNF includes:

- Chemical and Physical properties

- air oxidation rate

- wet dissolution rate

- $\quad$ surface area of the matrix

- $\quad$ clad failure fraction

- Free radionuclide inventory fraction

- $\quad$ gap radionuclide inventory fraction

- fuel area per package

- heat generation

- Radiological inventory

- $\quad$ Packaging

- Criticality controls 


\section{APPROACH}

A fuel type was selected to represent the group of fuels that had similar characteristics. This approach has been used in prior DOE fuel analysis and prior TSPA calculations. The representative fuel is selected based on 1) its quantity as compared to the total quantity of fuel in the group, and 2) the availability of characterization data. The representative fuel is not a "worst case" fuel in its characteristics, nor is it meant to be a composite fuel for the total inventory. The characterization data presented in this report was, however, extrapolated from the representative fuel so that the data represents the total inventory in the group.

\section{Chemical and Physical Properties}

\section{Air Oxidation Rate}

The air oxidation rates for the most part were unknown. There were a few cases where information could be extrapolated from existing data. The effect of the air oxidation rate on the DOE fuels is insignificant compared to the wet dissolution rate.

\section{Wet Dissolution Rate}

Wet dissolution is the primary method for making the radionuclides available for transport. There exists in the chemical literature a large compilation of dissolution data for unirradiated materials. There is very little data on the wet dissolution of irradiated materials. Where there were good models for wet dissolution they were used. Where no models existed, the model recommended was based on an extrapolation from an existing model.

\section{Surface Area of the Matrix}

The surface area was based on the known geometry of the representative fuel, except in a few cases where all of the fuel types in the group were considered. Where the existing geometry was unknown, estimates were made from similar known fuel types.

\section{Clad Failure Fraction}

The cladding failure fraction was based on known characterization data, or extrapolated from similar types of fuel.

\section{Free Radionuclide Inventory Fraction}

The free radionuclide inventory fraction was based on the fuel construction methods, the characteristics of the fuel matrix, the as stored condition of the fuel, and the treatment of the fuel that was projected.

\section{Gap Radionuclide Inventory Fraction}

The free radionuclide inventory fraction was based on the fuel construction methods, the characteristics of the fuel matrix, the as stored condition of the fuel, and the treatment of the fuel that was projected.

\section{Fuel Area per Package}


The fuel area per package was obtained from the surface area per gram of fuel and the envisioned packaging of the fuel.

\section{Heat Generation}

The heat generation was obtained from ORIGEN-2 generated data. The worst case fuel and package were used to give a worst case heat generation number.

\section{Radiological Inventory}

Radionuclide calculations have been performed for a variety of fuels currently in storage at the INEEL. The methodologies established for conducting these calculations has been reviewed by Quality Assurance. This evaluation showed that the methodology essentially meets the QA requirements for determining radionuclide inventories of the fuels currently stored at the INEEL.

ORIGEN-2 was used to perform the calculations. Where deemed adequate and applicable, the established cross-section libraries packaged with the program were used for the fuels. However, most of the INEEL fuels are NOT enveloped by the established ORIGEN-2 cross-section libraries and had to be generated from basic reactor physics parameters of the fuel, reactor, and operating environment.

For each cross-section library created the methodology, calculations, assumptions, and outputs were validated by a qualified individual familiar with ORIGEN-2 input parameter requirements. The QA review of the methods for both calculating the new libraries as well as the validation check was used to generate each cross-section library indicated that they essentially met the QA requirements.

If ORIGEN-2 values, or similar calculations from other programs, existed for a particular fuel type, the input parameters for the ORIGEN-2 code were evaluated. If the input parameters, assumptions, and calculations were satisfactory, compared to the existing QA reviewed methodology, the cross-section library was used for that particular fuel. When the input parameters were not satisfactory to the QA reviewed methodology, then they were recalculated.

\section{Packaging}

Packaging data was based on an analysis that included individually each fuel type in the group, rather than based on just the representative fuel.

\section{Criticality Controls}

A representative fuel type was chosen for each group, based on quantity of that fuel and the total quantity of fuel in the group. In some cases the representative fuel was not the largest contributer to the group, but a fuel on which there was existing data. The parameters for the group are those of the representative fuels. If there is variation in any parameter within the representative fuel, an average value was used. No attempt was made to use worst case values for the parameters in each group. Some fuels in a group could potentially have worse characteristics in a particular parameter than the representative fuel. But, because of the small quantity of the other fuel, it was decided that the parameter should not drive the projected performance of the whole group. As additional data becomes available these parameters may be modified. 


\section{Data Sources}

National SNF data base

Handbook of Chemistry and physics

Sandia PA on DOE SNF SAND-93-2330

Personal communications with

Dale Creasop, Matt Ebner, Henry Loo

Leroy Lewis, Lee Bendixon, Will Windes 


\section{DOE SNF Data Presented by Total System Performance Assessment Groups}

\subsection{Uranium Metal}

\section{Representative Fuel}

$\mathrm{N}$-reactor fuel was chosen to represent the group because its mass was so large that the performance of the rest of the groups fuels, even if they might be worse than $\mathrm{N}$-reactor fuel, would not change the overall group performance.

\section{Chemical and Physical Properties}

\section{Air Oxidation Rate}

No data exists for air oxidation of irradiated uranium metal. Data for unirradiated uranium metal exists, but the irradiated uranium metal may oxidize at a faster rate than the unirradiated uranium metal. RW presently uses zero for commercial SNF. The repository will be wet when the waste package is breached, and it was felt that the wet dissolution rate would be so much faster than the air oxidation that the air oxidation rate would be immaterial. For this reason the value was set to zero.

\section{Wet Dissolution Rate}

An existing dissolution model used by SNL was used for the uranium metal dissolution. This model was compared to two other models, one from the published literature and the other based on unclassified data. The SNL model was shown to be the most conservative (most rapid uranium dissolution) of the three models. The limited PNNL data for N-reactor fuel plus water indicates that classic uranium metal plus water oxidation rates would be a good first approximation of the rate. There needs to be additional research on irradiated uranium metal.

\section{Surface Area of the Matrix}

The surface area of the matrix is necessary because the release rate from corrosion of the matrix is dependent on the surface area. The uranium metal surface in an uncorroded condition would be relatively smooth and the surface area could be calculated from the geometric dimensions of the fuel. Because the Nreactor fuel is irradiated and corroded, the surface area is significantly larger, but not as high as commercial fuel that has a relatively rough surface with a large number of cracks and porosity. The ideal surface area is 1.4 E-5 $\mathrm{m}^{2} / \mathrm{g}$, assuming the largest size Mark IV element. A roughness factor of 5 to 10 should be used to account for the actual condition. A roughness factor of 5 was used making the surface area $7.0 \mathrm{E}-5 \mathrm{~m}^{2} / \mathrm{g}$.

\section{Clad Failure Fraction}

Much (50\%-80\%) of the $\mathrm{N}$-reactor fuel cladding is disrupted. No documentable characterization data exists on any of the cladding condition. A conservative approach is to assume that all of the cladding is failed and not give any credit for the protection of the fuel meat by the cladding. 


\section{Free Radionuclide Inventory Fraction}

The metallic uranium SNF will need to be dried and conditioned prior to packaging for the repository. Both of these treatments may involve heating the fuel. The heating may release some of the nongaseous fission products from the matrix and to the surface of the fuel where it will be available for immediate transport in the repository when the waste canister is breached. The spectrum of isotopes in the free inventory is not known. A fraction of the inventory for all isotopes is used for this parameter. Because of the heating process, the fraction for the $\mathrm{N}$-reactor fuel was set at 0.001 . There are no supporting analytical data for this value.

\section{Gap Radionuclide Inventory Fraction}

Because of the fuel manufacturing methods, there is no gap between the fuel meat and the cladding. Because of the cladding condition, if there were a gap inventory it would have been previously released to the environment. For this reason, the gap inventory fraction is set to zero.

\section{Fuel Area per Package}

An average loading of MTHM per package was determined from the MTHM and the package totals for all fuels in this category. This was used with the specific surface area determined above and appropriate conversion factors to calculate an average fuel meat surface area per package for this group. The value derived for this group is $1.4 \mathrm{E} 3 \mathrm{~m}^{2} /$ package.

\section{Heat Generation}

Based on data from Hanford, the worst case heat generation rate for $5 \mathrm{~N}$-reactor assemblies per canister is $17.5 \mathrm{w} /$ waste canister.

\section{Radiological Inventory}

The inveltory was developed from ORIGEN-2 runs for N-reactor fuel

\section{Packaging}

$2-17^{\prime \prime} \times 10^{\prime}$

$4-17^{\prime \prime} \times 15^{\prime}$

$101-24^{\prime \prime} \times 15^{\prime}$

\section{Criticality Controls}

Criticality analysis will be performed on each fuel types for transportation and storage of intact fuel assemblies and canisters. Criticality for the degraded modes will be performed on a worst case fuel. All of the fuel in this group is less than $2.5 \%$ enriched and will be packaged in large diameter disposal canisters. 


\subsection{Uranium - Zirconium Alloy}

\section{Representative Fuel}

Heavy Water Components Test Reactor (HWCTR) was chosen as the representative fuel because it was the largest part of the inventory.

\section{Chemical and Physical Properties}

\section{Air Oxidation Rate}

No data exists for this parameter. RW presently uses zero for commercial SNF. The repository will be wet when the waste package is breached, and it was felt that the wet dissolution rate would be so much faster that the air oxidation that the air oxidation rate would be immaterial. For this reason the value was set to zero.

\section{Wet Dissolution Rate}

It is believed that the addition of zirconium to the fuel matrix in the form of an alloy stabilizes the material so that it is not as reactive as pure uranium metal. There is some concern over the formation of an epsilon phase of uranium-zirconium alloy that is very reactive as a surface reaction in nitric acid. This did not seem to be as important in repository settings. It was decided to represent the fuel dissolution the same as uranium metal, see fuel group 1 . This is a conservative assumption.

\section{Surface Area of the Matrix}

Based on the element dimensions of the uranium matrix $(5.8 \mathrm{~cm} \mathrm{X} 290 \mathrm{~cm})$ with the fuel being a tube with a hollow center, the geometric surface area is calculated to be $1 \mathrm{~m}^{2}$. The uranium loading EOL averages $777 \mathrm{~g}$ Uranium. The calculated specific surface area is $1.3 \mathrm{E}-3 \mathrm{~m}^{2} / \mathrm{g}$. Adjusting this specific surface area with a roughness factor of 5 gives a surface area of $6.5 \mathrm{E}-3 \mathrm{~m}^{2} / \mathrm{g}$.

\section{Clad Failure Fraction}

The elements are tubes with some known to be leaking. No major damage has been identified. Assume 0.1 for the cladding failures fraction due to lack of any additional data.

\section{Free Radionuclide Inventory Fraction}

Because of the anticipated stability of the uranium-zirconium matrix and the intact cladding, it is not anticipated that there will be a large release of fission products into the waste container prior to container failure. The free radionuclide inventory fraction is assumed to be .00001 of the total radionuclide inventory because it is expected to be very low as compared to commercial SNF.

\section{Gap Radionuclide Inventory Fraction}

The fuel is formed without a gap between the fuel meat and the cladding. The gap inventory is set at zero because there is no gap. 


\section{Fuel Area per Package}

An average loading of MTHM per package was determined from the MTHM and the package totals for all fuels in this category. This was used with the specific surface area determined above and appropriate conversion factors to calculate an average fuel meat surface area per package for this group. The value derived for this group is $37 \mathrm{~m}^{2} /$ package.

\section{Heat Generation}

No heat generation data exists on these fuel types. Based on analysis of other fuel types of the same age it is believed that $10 \mathrm{w} /$ assembly is conservatively high. Nine assemblies are assumed to placed into one canister. The heat generation is estimated to be $90 \mathrm{w} /$ canister.

\section{Radiological Inventory}

There are no ORIGEN-2 generated data on any of the fuels in this group. The group is very small and can be represented by ORIGEN-2 generated data for the ATR fuel. This is justified because most of the fuel is old and it is believed of low burn-up.

\section{Packaging}

$2-17^{\prime \prime} \times 10^{\prime}$

$6-17^{\prime \prime} \times 15^{\prime}$

\section{Criticality Controls}

Criticality analysis will be performed on each fuel types for transportation and storage of intact fuel assemblies and canisters. Criticality for the degraded modes will be performed on a worst case fuel.

\subsection{Uranium - Molybdenum Alloy}

\section{Representative Fuel}

Fermi driver core 1 and 2 are the only fuel in the group.

\section{Chemical and Physical Properties}

\section{Air Oxidation Rate}

No data exists for this parameter. RW presently uses zero for commercial SNF. The repository will be wet when the waste package is breached, and it was concluded that the wet dissolution rate would be so much faster than the air oxidation that the air oxidation rate would be immaterial. For this reason the value was set to zero.

\section{Wet Dissolution Rate}

One study on unirradiated U-Mo alloy indicated that it corrodes at $1 \%$ of the rate of pure uranium metal. However, the microstructure at the grain boundaries could concentrate hydrides thus increasing 
reactivity over the long run, and also producing more particulates. This was proposed by Water in 1959 and suported by other publications. The rate was set at ten times the pure uranium metal rate because of the uncertainty in the long term performance.

\section{Surface Area of the Matrix}

Based on the geometry of the fuel pin $(.4 \mathrm{~cm} \mathrm{X} 84 \mathrm{~cm})$ and the pin uranium loading ( $134 \mathrm{~g} / \mathrm{pin})$, the surface area is calculated to be $8 \mathrm{E}-5 \mathrm{~m}^{2} / \mathrm{g}$. With a roughening factor of 5 , the surface area is $4 \mathrm{E}-4 \mathrm{~m} / \mathrm{g}$.

\section{Clad Failure Fraction}

Most of the Fermi fuel pins in this group are believed to have intact cladding. Some of the pins were melted and some also were declad. Assume 0.1 cladding failures fraction based on the existing data which shows of the 214 units, 2 have been melted, 6 segmented and 7 declad.

\section{Free Radionuclide Inventory Fraction}

Because of the anticipated stability of the uranium-molybdenum matrix and the intact cladding, it is not anticipated that there will be a large release of fission products into the waste container prior to container failure. The free radionuclide inventory fraction is assumed to be .00001 of the total radionuclide inventory because it is expected to be very low compared to commercial SNF.

\section{Gap Radionuclide Inventory Fraction}

The fuel is formed without a gap between the fuel meat and the cladding. The gap inventory is set at zero because there is no gap.

\section{Fuel Area per Package}

An average loading of MTHM per package was determined from the MTHM and the package totals for all fuels in this category. This was used with the specific surface area determined above and appropriate conversion factors to calculate an average fuel meat surface area per package for this group. The value derived for this group is $21 \mathrm{~m}^{2} /$ package.

\section{Heat Generation}

Based on ORIGEN-2 data, the worst case heat generation rate for the Fermi driver core is $1.1 \mathrm{w} /$ assembly. With 4 assemblies per waste canister, the worst case heat generation rate is $4.4 \mathrm{w} /$ waste canister.

\section{Radiological Inventory}

The radiological data was obtained from an ORIGEN-2 generation at INEEL based on known reactor parameters.

Packaging

$$
70-17^{\prime \prime} \times 10^{\prime}
$$




\section{Criticality Controls}

Criticality analysis will be performed on each fuel types for transportation and storage of intact fuel assemblies and canisters. Criticality for the degraded modes will be performed on a worst case fuel.

\section{4 Intact uranium Oxide}

\section{Representative Fuel}

Commercial fuel was chosen as the representative fuel because it was a significant part of the inventory and because there was a lot of data available on the fuel. There are many fuels in the group that are believed to perform better than commercial fuel and several fuels that have unknown performance characteristics.

\section{Chemical and Physical Properties}

\section{Air Oxidation Rate}

Limited data exists for this parameter. R.W. presently uses zero for commercial SNF. The repository will be wet when the waste package is breached, and it was felt that the wet dissolution rate would be so much faster that the air oxidation that the air oxidation rate would be immaterial. For this reason the value was set to zero.

\section{Wet Dissolution Rate}

A dissolution rate was used that was developed by R.W. for commercial SNF. This is conservative because much of the DOE SNF is not commercial, but has a ceramic matrix like Shippingport PWR, and will have a much slower dissolution rate.

\section{Surface Area of the matrix}

A value was derived from a number of references for commercial SNF, and is given as $9.5 \mathrm{E}-4 \mathrm{~m}^{2} / \mathrm{g}$.

\section{Clad Failure Fraction}

At the present time R.W. does not take credit for the cladding containing the fission products or protecting the fuel matrix. R.W. is evaluating taking cladding credit. For this analysis one should assume that $100 \%$ of the cladding is failed.

\section{Free Radionuclide Inventory Fraction}

The same as gap fraction

\section{Gap Radionuclide Inventory Fraction}

Based on the research at PNNL the gap inventory is isotope specific. From 0.01 to 0.02 fraction of these isotopes are found in the gap between the fuel matrix and the cladding and in the grain boundaries. For Cs, I, 
Se, and Tc 0.02 is used. For C, 0.01-0.06 fraction is used.

\section{Fuel Area per Package}

An average loading of MTHM per package was determined from the MTHM and the package totals for all fuels in this category. This was used with the specific surface area determined above and appropriate conversion factors to calculate an average fuel meat surface area per package for this group. The value derived for this group is $500 \mathrm{~m}^{2} /$ package.

\section{Heat Generation}

Based on repository requirements, the heat generation rate will be less than $1500 \mathrm{w} /$ assembly. If the commercial SNF is placed into a 21 assembly waste canister the total heat generation will be $31.5 \mathrm{~kW} /$ canister.

\section{Radiological Inventory}

The radiological data was obtained from an existing ORIGEN-2 run for commercial fuel, because commercial fuel is the representative fuel.

\section{Packaging}

$$
\begin{aligned}
& 68-17^{\prime \prime} \times 10^{\prime} \\
& 127-17^{\prime \prime} \times 15^{\prime} \\
& 5-24^{\prime \prime} \times 15^{\prime} \\
& 16-21 \text { assembly commercial canisters }
\end{aligned}
$$

\section{Criticality Controls}

Criticality analysis will be performed on each fuel types for transportation and storage of intact fuel assemblies and canisters. Criticality for the degraded modes will be performed on a worst case fuel. The HEU fuel will be co-disposed and the LEU fuel will be disposed in large diameter waste canisters.

\subsection{Failed Uranium Oxide}

\section{Representative Fuel}

TMI- 2 was chosen as the representative fuel because it comprises more than $90 \%$ of the mass of the group. There may be some fuels that perform worse than TMI-2, but the overall effect on the group performance would be negligible.

\section{Chemical and Physical Properties}

\section{Air Oxidation Rate}

No data exists for this parameter. R.W. presently uses zero for commercial SNF. The repository will be wet when the waste package is breached, and it was felt that the wet dissolution rate would be so much faster that the air oxidation that the air oxidation rate would be immaterial. For this reason the value was set to zero. 


\section{Wet Dissolution Rate}

The dissolution rate for commercial SNF was used for the disrupted SNF. For the TMI-2 fuel, the sections that were melted were converted into a ceramic type material that would have a lower dissolution rate. The fuel was exposed to water for many years, so any easily dissolved species would have been removed prior to repository emplacement.

\section{Surface Area of the Matrix}

Because of the reactor accident, the potential surface area will be larger than that of normal commercial SNF. It can be conservatively estimated that the surface area would be 100 times that of commercial SNF. Based on this assumption the surface area would be $9.5 \mathrm{E}-2 \mathrm{~m}^{2} / \mathrm{g}$ of material.

\section{Clad Failure Fraction} has failed.

Because of the disruptive nature of the TMI- 2 accident, it should be assumed that $100 \%$ of the cladding

\section{Free Radionuclide Inventory Fraction}

This value is included in the gap inventory.

\section{Gap Radionuclide Inventory Fraction}

Not all of the fuel was melted in the TMI-2 accident. There are many partial assemblies that still have their cladding intact, and potentially some gap inventory that has not been dissolved. A conservative estimate would be $1 \%$ of the isotopes that would normally be in the gap of commercial SNF.

\section{Fuel Area per Package}

Assuming an average uranium content for each of the waste packages and TMI- 2 canisters are packaged 4 to a waste package, using the surface area above the waste package will be $1.4 \mathrm{E}^{2} \mathrm{~m}^{2} /$ canister.

\section{Heat Generation}

Based on ORIGEN-2 data, the worst case heat generation rate for the TMI-2 fuel is $3.7 \mathrm{w} /$ assembly. The HIFR would have a higher heat generation rate, but at this time there is no data available. Based on the known ATR heat generation rate of $40 \mathrm{w} /$ assembly and the uranium-235 loading of the HIFR fuel assembly being 10 times the ATR fuel assembly the heat generation rate is assumed to be $400 \mathrm{w} /$ assembly. Loading two HIFR assemblies per canister gives a heat generation rate of $800 \mathrm{w} /$ canister.

\section{Radiological Inventory}

The inventory was derived from ORIGEN-2 data obtained for the TMI-2 core.

\section{Packaging}

$298-17^{\prime \prime} \times 10^{\prime}$

$388-17^{\prime \prime} \times 15^{\prime}$ 


\section{Criticality Controls}

Criticality analysis will be performed on each fuel types for transportation and storage of intact fuel assemblies and canisters. Criticality for the degraded modes will be performed on a worst case fuel. The HEU fuel will be co-disposed with HLW glass logs in the same waste canister, and the LEU fuel will be disposed in large diameter waste canisters.

\subsection{Uranium - Aluminum Based}

\section{Representative Fuel}

ATR represents only $40 \%$ of the mass of the group, but because there is good data available on the fuel it was chosen to represent the group.

\section{Chemical and Physical Properties}

\section{Air Oxidation Rate}

No data exists for the dry oxidation of irradiated aluminum. There is data for the air oxidation of unirradiated aluminum. In normal air oxidation, the extent of oxidation is self limiting at a given temperature. R.W. presently uses zero for commercial SNF. The repository will be wet when the waste package is breached, and it was felt that the wet dissolution rate would be so much faster that the air oxidation that the air oxidation rate would be immaterial. For this reason the value was set to zero.

\section{Wet Dissolution Rate}

A new dissolution rate has been proposed by the Savannah River Site(SRS). They have shown that the aluminum matrix and the enclosed uranium aluminide particles as a whole dissolve at a rate of $1 / 10$ that of uranium metal ( see group 1). This approximation is more representative for several different types of aluminum-based fuel than is the uranium metal model. For the uranium oxide matrix, the uranium oxide should dissolve at about the same rate as the aluminum matrix in repository conditions because of the small particle size. In addition many of the fission products will be in the aluminum matrix and will be released as the aluminum dissolves.

\section{Surface Area of the Matrix}

Based on the geometry of an ATR fuel assembly, the surface area is $1.3 \mathrm{E}-3 \mathrm{~m}^{2} / \mathrm{g}$. Using a roughening factor of 5 the surface area recommended is $6.5 \mathrm{E}-3 \mathrm{~m}^{2} / \mathrm{g}$.

\section{Clad Failure Fraction}

In the repository environment the aluminum cladding has a relatively short life expectancy. It is conservative not to take credit for the aluminum cladding and to assume that it is $100 \%$ failed.

\section{Free Radionuclide Inventory Fraction}

The fuel will be dried and some of the inventory may migrate into the free space. A conservative value of 0.0001 was selected. 


\section{Gap Radionuclide Inventory Fraction}

The aluminum-based fuel is formed without a gap, or by powder metallurgy, which essentially has no gap. The gap inventory will be less than that of commercial fuel so a value of 0 is appropriate.

\section{Fuel Area per Package}

An average loading of MTHM per package was determined from the MTHM and the package totals for all fuels in this category. This was used with the specific surface area determined above and appropriate conversion factors to calculate an average fuel meat surface area per package for this group. The value derived for this group is $210 \mathrm{~m}^{2} /$ package.

\section{Heat Generation}

Based on ORIGEN-2 data, the worst case ATR fuel has a heat generation rate of 40 w/assembly. Based on a waste canister loading of 12 ATR assemblies the worst case is 480 w/waste canister.

\section{Radiological Inventory}

The inventory was derived from ORIGEN-2 data obtained for the ATR core.

\section{Packaging}

$673-17^{\prime \prime} \times 10^{\prime}$

$33-17^{\prime \prime} \times 15^{\prime}$

\section{Criticality Controls}

Criticality analysis will be performed on each fuel types for transportation and storage of intact fuel assemblies and canisters. Criticality for the degraded modes will be performed on a worst case fuel. The uranium 235 enrichment in these fuels ranges from $10 \%$ to $95 \%$. The fuels will be co-disposed with HWL glass logs in the same waste container to ensure that criticality safety requirements are met.

\subsection{Uranium Silicide}

\section{Representative Fuel}

FRR - MTR from RERTR program is the only fuel in the group.

\section{Chemical and Physical Properties}

\section{Air Oxidation Rate}

No data exists for this parameter. RW presently uses zero for commercial SNF. The repository will be wet when the waste package is breached, and it was felt that the wet dissolution rate would be so much faster that the air oxidation that the air oxidation rate would be immaterial. For this reason the value was set to zero.

Wet Dissolution Rate 
A new dissolution rate has been proposed by SRS. They have shown that the aluminum matrix and the enclosed uranium aluminide particles dissolve at a rate of $1 / 10$ that of uranium metal. This approximation is more representative for several different types of aluminum-based fuel than is the uranium metal model.

\section{Surface Area of the Matrix}

This fuel is designed to be a replacement fuel for the HEU aluminum-based fuel, but will be less than $20 \%$ enriched rather than the $93 \%$ enriched fuel. Based on input from Savannah River the surface area recommended is $1.4 \mathrm{E}-2 \mathrm{~m}^{2} / \mathrm{g}$.

\section{Clad Failure Fraction}

In the repository environment the aluminum cladding has a relatively short life expectancy. It is conservative not to take credit for the aluminum cladding and to assume that it is $100 \%$ failed.

\section{Free Radionuclide Inventory Fraction}

The fuel will be dried and some of the inventory may migrate into the free space. A conservative value of 0.0001 was selected.

\section{Gap Radionuclide Inventory Fraction}

The aluminum-based fuel is formed without a gap, or by powder metallurgy, which essentially has no gap. The gap inventory will be less than that of commercial fuel so a value of 0 is appropriate.

\section{Fuel Area per Package}

An average loading of MTHM per package was determined from the MTHM and the package totals for all fuels in this category. This was used with the specific surface area determined above and appropriate conversion factors to calculate an average fuel meat surface area per package for this group. The value derived for this group is $85 \mathrm{~m}^{2} /$ package.

\section{Heat Generation}

No data for this fuel group or representative fuel presently exists. Assuming ATR data of $40 \mathrm{w} /$ assembly and a loading of 35 assemblies / canister, the heat loading is $1.4 \mathrm{~kW} /$ canister.

\section{Radiological Inventory}

There is no ORIGEN-2 data available for this fuel. The fuel will be represented by ATR fuel. This is conservative because the ATR fuel will have much higher burn-up than the MTR fuel.

\section{Packaging}

$165-17^{\prime \prime} \times 10^{\prime}$

$50-17^{\prime \prime} \times 15^{\prime}$ 


\section{Criticality Controls}

Criticality analysis will be performed on each fuel types for transportation and storage of intact fuel assemblies and canisters. Criticality for the degraded modes will be performed on a worst case fuel. The uranium 235 enrichment in these fuels ranges from $8 \%$ to $95 \%$. The fuels will be co-disposed to ensure that criticality safety requirements are met.

\subsection{High Integrity Uranium-Thorium Carbide}

\section{Representative Fuel}

Fort St. Vrain Reactor is selected as it is $95 \%$ of the mass of the group. There is some fuel that may perform worse than FSVR fuel but its effect on the group is negligible.

\section{Chemical and Physical Properties}

\section{Air Oxidation Rate}

No data exists for air oxidation of this irradiated fuel. Data does exist for the air oxidation of unirradiated carbon and graphite. RW presently uses zero for commercial SNF. The repository will be wet when the waste package is breached, and it was felt that the wet dissolution rate would be so much faster than the air oxidation rate that the air oxidation rate would be immaterial. The uranium carbide may react with the air when the silicon carbide coating is breached. Presently less than $1 \%$ of the particles are breached. If the uranium or thorium carbides react with air, they will produce uranium oxide, that will dissolve much slower in the repository than will the uranium carbide, which is assumed. Neglecting the oxidation is a conservative assumption. No reaction is expected between the silicon carbide and the air.

\section{Wet Dissolution Rate}

The rate of dissolution of the uranium carbide particles is controlled by the dissolution of the silicon carbide particle. The uranium carbide is believed to rapidly react with water. The model proposed for use with this fuel is for silicon carbide dissolution and assumes that the uranium dissolves at the same rate as the silicon carbide. The fuel has a very large number of particles of which some will rupture faster that others. Therefore, a linear approximation or the dissolution rate may adequately represent the dissolution of the fuel in an assembly.

\section{Surface Area of the Matrix} heavy metal.

Based on design parameters the surface area ranges from $5.9 \mathrm{E}-3 \mathrm{~m}^{2} / \mathrm{g}$ heavy metal to $2.2 \mathrm{E}-2 \mathrm{~m}^{2} / \mathrm{g}$

\section{Clad Failure Fraction}

Analysis of the fuel after irradiation indicated less than a $1 \%$ failure of the particles.

\section{Free Radionuclide Inventory Fraction}

The silicon carbide coating is very impervious to fission product transport. The pyrolitic carbon coating is also impervious except for cesium. Based on this, the fission product distribution among all of the elements and the less than $1 \%$ coating failure, the free inventory fraction is less than 0.00001 . The contribution of the 
P.B. core 2 fuel was neglected because of the small contribution to the MTHM of the group.

\section{Gap Radionuclide Inventory Fraction}

The pyrolytic carbon coating was designed to absorb fission products, so the gap inventory should be zero. The contribution of the P.B. core 2 fuel was neglected because of the small contribution to the MTHM of the group.

\section{Fuel Area per Package}

An average loading of MTHM per package was determined from the MTHM and the package totals for all fuels in this category. This was used with the specific surface area determined above and appropriate conversion factors to calculate an average fuel meat surface area per package for this group. The value derived for this group is $1100 \mathrm{~m}^{2} /$ package.

\section{Heat Generation}

The heat generation rate for the FSVR fuel is estimated to be $50 \mathrm{w} /$ assembly. With 5 assemblies in a canister the heat generation rate is $250 \mathrm{w} /$ canister.

\section{Radiological Inventory}

The radiological data is based on ORIGEN-2 data for the Fort St. Vrain fuel.

\section{Packaging}

$503-17^{\prime \prime} \times 15^{\prime}$

\section{Criticality Controls}

Criticality analysis will be performed on each fuel types for transportation and storage of intact fuel assemblies and canisters. Criticality for the degraded modes will be performed on a worst case fuel. The fuel is all $\mathrm{HEU}$ and will be co-disposed with HLW glass logs in the same waste container.

\subsection{Low Integrity Uranium-Thorium Carbide}

\section{Representative Fuel}

Peachbottom core 1 is the only fuel in the group. Peachbottom core 2 is included in group 8 because it's fuel particles are basically intact and are more rugged than the P.B.-1 particles.

\section{Chemical and Physical Properties}

\section{Air Oxidation Rate}

No data exists for air oxidation of this irradiated fuel. Data does exist for the air oxidation of unirradiated carbon and graphite. R.W. presently uses zero for commercial SNF. The repository will be wet when the waste package is breached, and it was felt that the wet dissolution rate would be so much faster than the 
air oxidation rate that the air oxidation rate would be immaterial. The uranium carbide may react with the air when the particle coating is breached. Presently $60 \%$ of the particles are breached. If the uranium or thorium carbides react with air, they will produce uranium oxide, that will dissolve much slower in the repository than the uranium carbide, which is assumed. Neglecting the oxidation of the carbide is a conservative assumption. The oxidation of the uranium carbide will potentially release some fission products from the fuel matrix that could accumulate in the gap for early release. These will be accounted for in an increased gap inventory.

\section{Wet Dissolution Rate}

The fuel particles in this fuel group do not have a silicon carbide coating. The reaction rate of the uranium carbide with water is expected to be rapid. The pyrolytic carbon coating is not expected to give much protection to the uranium carbide from water attack. Because there is no other model available, this dissolution rate should be treated as 10 times the value of the metal dissolution rate. This includes the effects of direct water contact with the particle through graphite deterioration and the permeation rate of water through the graphite.

\section{Surface Area of the Matrix}

Based on the similar design parameters to the FSVR fuel the surface area ranges from $5.9 \mathrm{E}-3 \mathrm{~m}^{2} / \mathrm{g}$ heavy metal to $2.2 \mathrm{E}-2 \mathrm{~m}^{2} / \mathrm{g}$ heavy metal.

\section{Clad Failure Fraction}

Based on fuel examination $60 \%$ to $80 \%$ of the fuel particles of the peachbottom core 1 are failed. Assume a cladding failure fraction of 0.6 to 0.8 .

\section{Free Radionuclide Inventory Fraction}

The fuel will be dried and some of the inventory may migrate into the free space. A conservative fraction value of 0.1 was selected because characterization data has shown that many fission products ( $\mathrm{Cs}, \mathrm{Ba}$, $\mathrm{Sr}, \mathrm{H}, \mathrm{C}$ ) were released from the fuel particles and were removed by the purge gas and deposited in the fission product trap inside the assembly.

\section{Gap Radionuclide Inventory Fraction}

The pyrolytic carbon coating was designed to absorb fission products. For those fuel particles that are breached some fission products may accumulate after they are released from the air oxidation of the uranium carbide. The gap inventory will be assumed to be 0.001 of the inventory.

\section{Fuel Area per Package}

An average loading of MTHM per package was determined from the MTHM and the package totals for all fuels in this category. This was used with the specific surface area determined above and appropriate conversion factors to calculate an average fuel meat surface area per package for this group. The value derived for this group is $610 \mathrm{~m}^{2} /$ package.

\section{Heat Generation}

Based on ORIGEN-2 data the maximum projected heat rate for the Peach Bottom fuel is $3.7 \mathrm{w} /$ 
assembly. Based on a loading of 10 assemblies per canister the heat generation rate is $37 \mathrm{w} /$ canister.

\section{Radiological Inventory}

The radiological inventory was determined from ORIGEN-2 generated data for Peachbottom core 1 fuel.

\section{Packaging}

$60-17^{\prime \prime} \times 15^{\prime}$

\section{Criticality Controls}

Criticality analysis will be performed on each fuel types for transportation and storage of intact fuel assemblies and canisters. Criticality for the degraded modes will be performed on a worst case fuel. The fuel is all HEU and will be co-disposed with HLW glass logs in the same waste container.

\subsection{Non-Graphite Uranium Carbide}

\section{Representative Fuel}

FFTF carbide assemblies were chosen to represent the group because they make up $70 \%$ of the group and they contains both uranium and plutonium. The FFTF carbide fuel was constructed from uncoated uranium and plutonium carbide spheres that were loaded directly into the fuel pins, or were pressed into pellets that were loaded into the pins.

\section{Chemical and Physical Properties}

\section{Air Oxidation Rate}

No data exists for this parameter. R.W. presently uses zero for commercial SNF. The repository will be wet when the waste package is breached. It was assumed that the wet dissolution rate would be so much faster than the air oxidation, that the air oxidation rate would be immaterial. If the uranium or plutonium carbides react with air, they will produce oxides, that will dissolve much slower in the repository than the carbides that are assumed in the model. Neglecting the oxidation is a conservative assumption. The oxidation of the carbides will potentially release some fission products from the fuel matrix that could accumulate in the gap for early release. These will be accounted for in an increased gap inventory.

\section{Wet Dissolution Rate}

The reaction rate of the uranium carbide with water is expected to be rapid. There is no coating to give protection to the uranium carbide from water attack. Because there is no other model available, this dissolution rate should be treated as 100 times the value of the metal dissolution rate.

\section{Surface Area of the Matrix}

Based on a particle size of 200 um the surface area is $2.6 \mathrm{E}-3 \mathrm{~m}^{2} / \mathrm{g}$ 


\section{Clad Failure Fraction}

The cladding is stainless steel and there are no reports of damage. Assume that 0.1 fraction of the cladding is failed, based on a lack of additional information.

\section{Free Radionuclide Inventory Fraction}

Included in the gap inventory.

\section{Gap Radionuclide Inventory Fraction}

Based on the similarity between the construction of the FFTF and commercial SNF this fuel is treated as Commercial SNF. Research at PNNL found the gap inventory for commercial SNF is isotope specific. From 0.1 to 0.2 fraction of these isotopes are found in the gap between the fuel matrix and the cladding and in the grain boundaries. For Cs, I, Se, and Tc 0.02 is used. For C, 0.01-0.06 is used.

\section{Fuel Area per Package}

An average loading of MTHM per package was determined from the MTHM and the package totals for all fuels in this category. This was used with the specific surface area determined above and appropriate conversion factors to calculate an average fuel meat surface area per package for this group. The value derived for this group is $86 \mathrm{~m}^{2} /$ package.

\section{Heat Generation}

The heat generation rate for the FFTF assembly is estimated to be $1800 \mathrm{w} /$ assembly. The fuel will be loaded one assembly per canister resulting in a heat generation rate of $1800 \mathrm{w} /$ canister.

\section{Radiological Inventory}

The radiological inventory is derived from ORIGEN-2 runs.

\section{Packaging}

$3-17^{\prime \prime} \times 10^{\prime}$

$2-17^{\prime \prime} \times 15^{\prime}$

\section{Criticality Controls}

Criticality analysis will be performed on each fuel types for transportation and storage of intact fuel assemblies and canisters. Criticality for the degraded modes will be performed on a worst case fuel. The effective enrichment of this fuel is greater than $15 \%$. The fuel will be co-disposed with HLW glass logs in the same waste canister to control criticality. 


\subsection{Mixed Oxide Fuel (MOX)}

Representative Fuel

FFTF MOX test assembly was chosen as the representative fuel because it comprises more than $80 \%$ of the group.

\section{Chemical and Physical Properties}

\section{Air Oxidation Rate}

No data exists for this parameter. RW presently uses zero for commercial SNF. The repository will be wet when the waste package is breached, and it was felt that the wet dissolution rate would be so much faster that the air oxidation that the air oxidation rate would be immaterial. For this reason the value was set to zero.

\section{Wet Dissolution Rate}

A dissolution rate was used that was developed by RW for commercial SNF. A better dissolution model for plutonium oxide was not available.

\section{Surface Area of the Matrix}

The fuel is constructed similar to commercial fuel. Therefore, the surface area should be the same as commercial fuel, so $9.5 \mathrm{E}-4 \mathrm{~m}^{2} / \mathrm{g}$ should be used.

\section{Clad Failure Fraction}

There is no data on this value. The fuel is stainless steel clad and an assumption of 0.1 fraction failures is made based on other stainless steel clad SNF.

\section{Free Radionuclide Inventory Fraction}

the same as gap fraction.

\section{Gap Radionuclide Inventory Fraction}

Based on the research at PNNL on commercial SNF, the gap inventory is isotope specific. An inventory fraction of 0.01 to 0.02 of these isotopes are found in the gap between the fuel matrix and the cladding and in the grain boundaries. For Cs, I, Se, and Tc $2 \%$ is used. For C, 0.01-0.06 is used.

\section{Fuel Area per Package}

An average loading of MTHM per package was determined from the MTHM and the package totals for all fuels in this category. This was used with the specific surface area determined above and appropriate conversion factors to calculate an average fuel meat surface area per package for this group. The value derived for this group is $36 \mathrm{~m}^{2} /$ package. 


\section{Heat Generation}

It is estimated that the heat generation rate for an FFTF assembly is $1.8 \mathrm{~kW}$. It will be loaded one assembly per canister.

\section{Radiological Inventory}

The radiological inventory data was derived from data developed in an ORIGEN-2 run for FFTF oxide fuel.

\section{Packaging}

$38-17^{\prime \prime} \times 19^{\prime}$

$32917^{\prime \prime} \times 15^{\prime}$

\section{Criticality Controls}

Criticality analysis will be performed on each fuel types for transportation and storage of intact fuel assemblies and canisters. Criticality for the degraded modes will be performed on a worst case fuel. The effective enrichment of the MOX fuel is greater than $15 \%$. The fuel will be co-disposed with HLW glass logs in the same waste container to control criticality.

\subsection{Uranium-Thorium Oxide}

\section{Representative Fuel}

Shippingport LWBR was chosen as the representative fuel because it represented more than $75 \%$ of the inventory in this group, and there was good data available on the fuel.

\section{Chemical and Physical Properties}

\section{Air Oxidation Rate}

No data exists for this parameter. RW presently uses zero for commercial SNF. The repository will be wet when the waste package is breached, and it was felt that the wet dissolution rate would be so much faster than the air oxidation that the air oxidation rate would be immaterial. For this reason the value was set to zero.

\section{Wet Dissolution Rate}

The Shippingport fuel matrix is a uranium oxide / thorium oxide formed into ceramic pellets. A ceramic dissolution model is proposed for the dissolution rate.

\section{Surface Area of the Matrix}

Based on the geometry and the uranium loading of a fuel pellet including a roughness factor of 5 , the surface area is $5 \mathrm{E}-4 \mathrm{~m}^{2} / \mathrm{g}$ 


\section{Clad Failure Fraction}

Based on the known $7 \%$ of the inventory that has been destructively examined, it is estimated that 0.1 fraction of the cladding has failed.

\section{Free Radionuclide Inventory Fraction}

This fraction is included in gap fraction.

\section{Gap Radionuclide Inventory Fraction}

The fuel construction is very similar to commercial fuel. Based on the research at PNNL on commercial SNF, the gap inventory is isotope specific. From 0.01 to 0.02 fraction of these isotopes are found in the gap between the fuel matrix and the cladding and in the grain boundaries. For Cs, I, Se, and Tc 0.02 is used. For C, $0.01-0.06$ is used.

\section{Fuel Area per Package}

An average loading of MTHM per package was determined from the MTHM and the package totals for all fuels in this category. This was used with the specific surface area determined above and appropriate conversion factors to calculate an average fuel meat surface area per package for this group. The value derived for this group is $350 \mathrm{~m}^{2} /$ package.

\section{Heat Generation}

Based on ORIGEN-2 data for Shippingport LWBR fuel, the maximum heat generation rate is 120 w/assembly. The fuel will be packaged 1 assemble per canister.

\section{Radiological Inventory}

The radionuclide inventory was determined using data from an ORIGEN-2 run for the LWBR fuel

\section{Packaging}

$$
\begin{aligned}
& 15-17^{\prime \prime} \times 10^{\prime} \\
& 9-17^{\prime \prime} \times 15^{\prime} \\
& 3-24^{\prime \prime} \times 15^{\prime}
\end{aligned}
$$

\section{Criticality Controls}

Criticality analysis will be performed on each fuel types for transportation and storage of intact fuel assemblies and canisters. Criticality for the degraded modes will be performed on a worst case fuel. This HEU fuel will be co-disposed with HLW glass logs in the same waste container, to ensure criticality safety. 


\subsection{Uranium-Zirconium-Hydride}

\section{Representative Fuel}

TRIGA comprises more than $90 \%$ of this group.

\section{Chemical and Physical Properties}

\section{Air Oxidation Rate}

No data exists for this parameter. RW presently uses zero for commercial SNF. The repository will be wet when the waste package is breached, and it was felt that the wet dissolution rate would be so much faster than the air oxidation that the air oxidation rate would be immaterial. For this reason the value was set to zero.

\section{Wet Dissolution Rate}

No dissolution data could be found on this matrix. The INEEL experience is that it dissolves very slowly. The material that has been exposed to water over many years is still shiny and shows no signs of attack. It can be represented by $1 / 10$ of the value of the commercial SNF rate.

\section{Surface Area of the Matrix}

Based on geometry and the uranium loading per rod, with a surface roughening factor of 5 the surface area is $1 \mathrm{E}-4 \mathrm{~m}^{2} / \mathrm{g}$.

\section{Clad Failure Fraction}

Based on the fraction of the fuel that is either declad or that is aluminum clad for which no cladding credit is taken, the fraction of failed cladding is 0.10 .

\section{Free Radionuclide Inventory Fraction}

Because of the anticipated stability of the uranium-zirconium hydride matrix, the stability of the $\mathrm{ZrO}$ layer on the outside of the fuel matrix, and the intact cladding, it is not anticipated that there will be a large release of fission products into the waste container prior to container failure. The free radionuclide inventory fraction is assumed to be .00001 of the total radionuclide inventory.

\section{Gap Radionuclide Inventory Fraction}

The fission products are contained well in the matrix, but there is a design gap between the matrix and the cladding. The gap inventory fraction should be 0.00001 .

\section{Fuel Area per Package}

An average loading of MTHM per package was determined from the MTHM and the package totals for all fuels in this category. This was used with the specific surface area determined above and appropriate conversion factors to calculate an average fuel meat surface area per package for this group. The value derived 
for this group is $2 \mathrm{~m}^{2} /$ package.

\section{Heat Generation}

Based on ORIGEN-2 data for TRIGA fuel, the maximum heat generation rate is 1 w/assembly. The fuel will be packaged 100 assemblies per canister making the heat generation rate $100 \mathrm{w} /$ assembly.

\section{Radiological Inventory}

The radionuclide inventory was derived from ORIGEN-2 runs for TRIGA fuel.

\section{Packaging}

$92-17^{\prime \prime} \times 10^{\prime}$

$8-17^{\prime \prime} \times 15^{\prime}$

\section{Criticality Controls}

Criticality analysis will be performed on each fuel types for transportation and storage of intact fuel assemblies and canisters. Criticality for the degraded modes will be performed on a worst case fuel. The fuel is $\mathrm{HEU}$ and will be co-disposed.

\subsection{Miscellaneous}

\section{Representative Fuel}

None. The largest fuel, as measured in MTHM is a miscellaneous fuel at ANL-W that is most likely uranium metal or alloy. The other two largest contributors are identified as uranium alloy and uranium-thorium alloy. These make up more than $80 \%$ of the MTHM in the group. It is conservative to treat the total group as metal. The fuel will be modeled like it is for N-Reactor fuel, because N-Reactor fuel has the worst overall performance parameters of the DOE SNF planned for repository disposal.

\section{Chemical and Physical Properties}

\section{Air Oxidation Rate}

No data exists for air oxidation of these irradiated materials. R.W. presently uses zero for commercial SNF. The repository will be wet when the waste package is breached, and it was felt that the wet dissolution rate would be so much faster that the air oxidation than the air oxidation rate would be immaterial. For this reason the value was set to zero.

\section{Wet Dissolution Rate}

There is a large variety of fuel in this group, from metal to oxide to nitride to salt. Many of these fuels are not well characterized. The largest fuel, as measured in MTHM is a miscellaneous fuel at ANL-W that is most likely uranium metal or alloy. The other two largest contributors are identified as uranium alloy and uranium-thorium alloy. These make up more than $80 \%$ of the MTHM in the group. It is conservative to treat the 
total group as metal (see group one discussion).

\section{Surface Area of the Matrix}

The surface area of the matrix is necessary because the release rate from corrosion of the matrix is dependent on the surface area. The uranium metal surface in an uncorroded condition would be relatively smooth and the surface area could be calculated from the geometric dimensions of the fuel. Because the $\mathrm{N}$-reactor fuel is irradiated and corroded, the surface area is significantly larger, but not as high as commercial fuel that has a relatively rough surface with a large number of cracks and shattering. The ideal surface area is $1.4 \mathrm{E}-5 \mathrm{~m}^{2} / \mathrm{g}$, assuming the largest size Mark IV element. A roughening factor of 5 to 10 should be used to account for the actual condition. A roughening factor of 5 was used making the surface area $7.0 \mathrm{E}-5 \mathrm{~m}^{2} / \mathrm{g}$

\section{Clad Failure Fraction}

Much of the fuel in this group is scrap from fuel development programs and from analysis of fuel remains. No documentable characterization data exists on any of the cladding condition. A conservative approach is to assume that all of the cladding is failed and not give any credit for the protection of the fuel meat by the cladding.

\section{Free Radionuclide Inventory Fraction}

The metallic uranium SNF will need to be dried and conditioned prior to packaging for the repository. Both of these treatments may involve heating the fuel. The heating may release some of the fission products from the matrix and into the canister where it will be available for immediate transport in the repository when the waste canister is breached. The spectrum of isotopes in the free inventory is not known. A fraction of the inventory for all isotopes is used for this parameter. Because of the heating process, the fraction for the $\mathrm{N}$ reactor was set a 0.001 . The same value is used for this group. There are no supporting analytical data for this value.

\section{Gap Radionuclide Inventory Fraction}

Because of the fuel manufacturing methods for N-reactor fuel, there is no gap between the fuel meat and the cladding. Because of the cladding condition of $\mathrm{N}$-reactor fuel, if there were a gap inventory it would have been previously released to the environment. The gap inventory fraction is set to zero. The same value is used for this group because it is represented by $\mathrm{N}$-reactor fuel.

\section{Fuel Area per Package}

An average loading of MTHM per package was determined from the MTHM and the package totals for all fuels in this category. This was used with the specific surface area determined above and appropriate conversion factors to calculate an average fuel meat surface area per package for this group. The value derived for this group is $17 \mathrm{~m}^{2} /$ package.

\section{Heat Generation}

Most of this fuel is old and has very small heat generation rates. Because there is no data available and worst case heat generation rate data is wanted, it will be assumed that the heat generation rate will be less than commercial SNF or $31.5 \mathrm{~kW} /$ canister. 


\section{Radiological Inventory}

Because of the lack of data on the fuel, assume that the radiological data is the same as commercial fuel.

\section{Packaging}

$24-17^{\prime \prime} \times 10^{\prime}$

$20-16^{\prime \prime} \times 15^{\prime}$

\section{Criticality Controls}

Criticality analysis will be performed on each fuel types for transportation and storage of intact fuel assemblies and canisters. Criticality for the degraded modes will be performed on a worst case fuel. Much or the fuel is HEU and will be disposed with mass limits for criticality control. 